\title{
CRITERIOS DE CALIFICACIÓN EN LOS DEPORTES DE LOS JUEGOS PARALÍMPICOS, LONDRES - 2012
}

\section{QUALIFICATION CRITERIA FOR SPORTS IN THE PARALYMPIC GAMES, LONDON - 2012}

\author{
Verónica Velásquez Rodriguez ${ }^{1}$ \\ 1 Profesional en Cultura Física, Deporte y Recreación. e-mail: vr.veronica@gmail.com
}

Rev. U.D.C.A Act. \& Div. Cient. 15(Supl. Olimpismo): 105 - 121, 2012
RESUMEN

El deporte es uno de los fenómenos sociales más importantes de nuestro tiempo y es donde se producen y se expresan los valores de la sociedad. El deporte paralímpico, como una manifestación de esto, ha sido de alto impacto social y deportivo, sin duda de interés para la población en general, por lo que en esta revisión, se incluyen los datos de información acerca de su estructura, los deportes y su evolución técnica, para llegar a los criterios de clasificación en los Juegos Paralímpicos de Londres, 2012, siendo estos temas de especial interés para la comunidad deportiva. Con ello, se pretende dar al lector una visión general sobre las normas generales que rigen el deporte paralímpico en el mundo y su filosofía.

Palabras clave: Deporte paralímpico, criterios de selección, elegibilidad.

\section{SUMMARY}

Sport is one of the most important social phenomena of our time and is where the values of society are produced and expressed. Paralympic sport as its manifestation has been of high social and sport impact, certainly of interest to the general public. In this review article, general details about its structure, the sports and technical evolution of the Paralympic sport is covert in order to reach the criteria for classification in the Paralympic Games London-2012, being these issues of particular interest to the sport community. This way, is it intended to give the reader an overview regarding the general rules governing the Paralympic sport in the world and its philosophy.

Key words: Paralympic Sport, selection criteria, eligibility.

\section{INTRODUCCIÓN}

El mismo día de la Ceremonia inaugural de los Juegos Olímpicos de Londres, en 1948, se celebró un evento deportivo al norte de la capital inglesa, en un pueblo cercano a la población de Aylesbury, en el centro nacional de lesiones de columna vertebral, en el hospital Stoke Mandeville. Estos Juegos fueron organizados por el médico judío Ludwig Guttmann, un neurocirujano, entusiasta y con algunas ideas muy revolucionarias sobre el tratamiento de las lesiones de médula espinal. Su enfoque incluía cuidados personales individuales y una evaluación clínica durante los primeros días posteriores a la lesión. Complementaba la metodología con una gran determinación para volver a encender la llama del espíritu interno de sus pacientes. Eligió el deporte, como medio para alcanzar dicho objetivo (Sainsbury, 2004). De allí que Guttmann consiguiera que en los Juegos de Roma de 1960, se realizaran los primeros Juegos Paralímpicos, posteriores a los Juegos Olímpicos, hasta la fecha.

Actualmente, el deporte es utilizado como medio de rehabilitación, pero para varias personas discapacitadas en todo el mundo, el deporte hace parte de sus actividades diarias habituales. Los deportistas Paralímpicos han hecho que su rendimiento y logros sean comparables a los de sus colegas sin discapacidad, haciendo de la máxima justa del deporte Paralímpico una exhibición equivalente a los Juegos Olímpicos. Así, los juegos Paralímpicos se convierten no sólo en un evento sublime sino, además, de ejemplo para el mundo en los procesos de inclusión social y desarrollo. Es así como el autor Cayuela (1997) afirma en su articulo sobre los efectos sociales del deporte que "quizá el mejor ejemplo de integración social a través del deporte lo encontremos en la organización de competiciones para discapacitados físicos y sensoriales, que tienen su máxima manifestación en la celebración de los Juegos Paralímpicos". 
Posteriormente a los Juegos Paralímpicos, celebrados en 1960, en los Juegos de Barcelona 1992, se inician los estudios de clasificación funcional enfocados por deporte, con el fin de buscar resultados de alto nivel y en equidad. Los métodos de clasificación funcional son revisados en 2003 y en 2007, el código de clasificación del IPC es aprobado y firmado (extractado de la página oficial del IPC (2012).

En la actualidad, en las guías de clasificación a los Juegos Paralímpicos, se encuentran plasmados los criterios deportivos, de elegibilidad y de clasificación funcional requeridos en cada deporte, convirtiéndose en la carta de navegación de los comités paralímpicos nacionales, para conseguir sus cupos de participación en las Paralimpíadas. Teniendo en cuenta que esta normativa es general y también existe por deportes, se enunciará una descripción de las normas generales y otra descripción por cada uno de los deportes convocados en el programa de los juegos paralímpicos de Londres 2012, teniendo en cuenta que el IPC en su estructura reconoce el gobierno de algunos deportes por parte de las organizaciones internacionales y, en otros casos, existen deportes que son exclusivos de su gobierno; para ampliar esta información, se ilustra la estructura del IPC (Figura 1) y el gobierno de los deportes paralímpicos, según la estructura internacional que, para tal fin, ha desarrollado el Comité Paralímpico Internacional - IPC.
Estructura General del Comité Paralímpico Internacional: La estructura del Comité Paralímpico Internacional esta compuesta por las Federaciones Internacionales por deporte, las cuales, son denominadas con la sigla IF's (International Sports Federation), que actúan en la asamblea del IPC con voz y voto y en total son once; del mismo modo, las Organizaciones Internacionales de Deportes para personas Discapacitadas, que en este articulo serán denominadas IOSD's (International Organization of Sport for the Disabled), también actúan con voz y voto en la Asamblea del IPC y son en total cuatro; los Comités Paralímpicos Nacionales, que en adelante serán denominados como NPC's (National Paralympic Committees), actúan con voz y voto en las asambleas del IPC y en total son $170 \mathrm{y}$, por último, pero no menos importantes, los Comités Paralímpicos Regionales, que actúan con voz y voto en las asambleas del IPC y en la actualidad son cinco. Partiendo de la estructura del comité paralímpico internacional (Cuadro 1), los deportes paralímpicos se dividen en tres grupos, según el gobierno a cual pertenezcan; así: Deportes de gobierno de las Federaciones Internacionales por Deporte (IF's): Arquería (FITA), Ciclismo (UCI), Ecuestre (FEI), Para Canoe (ICF), Remo (FISA), Navegación (IFDS), Tenis de Mesa (ITTF), Para Triatlon, Voleyball Sentado (WOVD), Baloncesto en Silla de ruedas (IWBF), Tenis en silla de Ruedas (ITF), Rugby en silla de ruedas (IWRF) y Curling en Silla de Ruedas (WCF). Extractado del sitio web del Comité Paralímpico Internacional (2012).

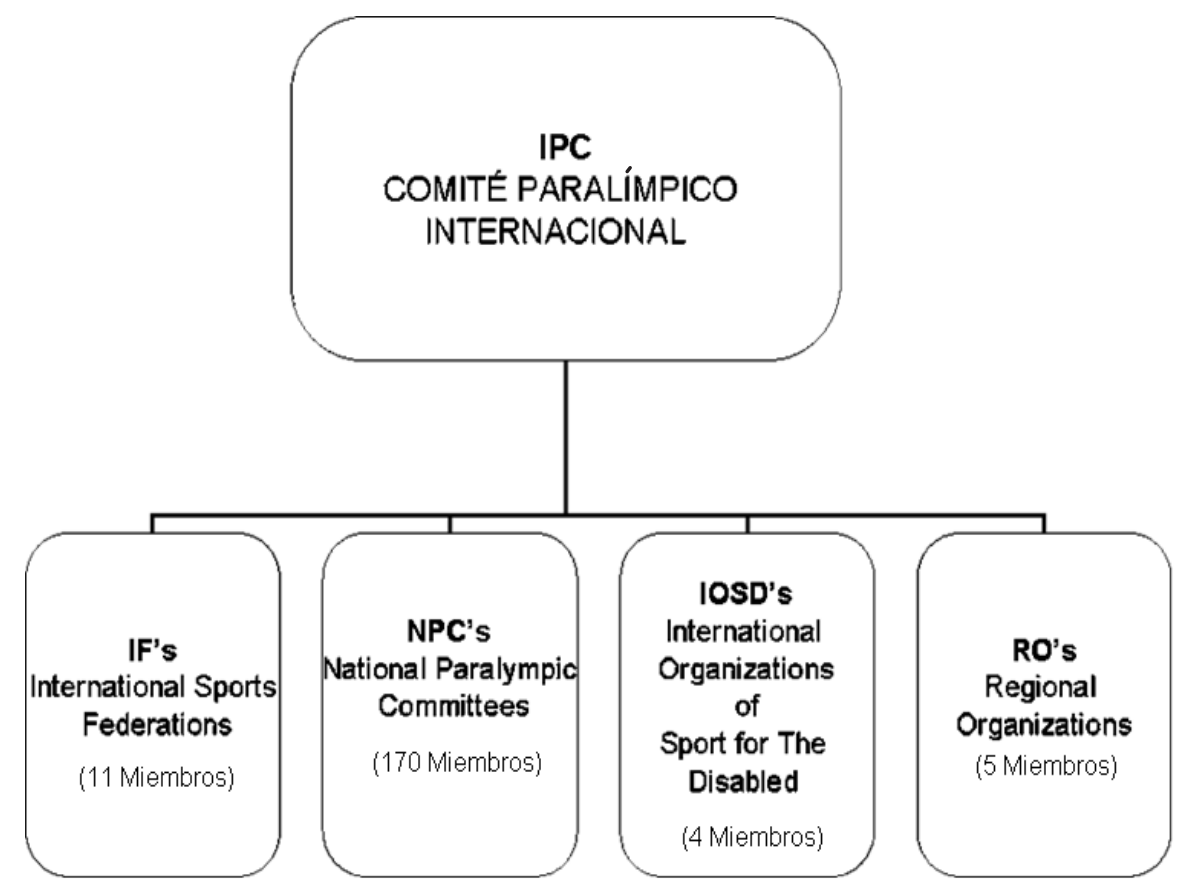

Figura 1: Estructura del Comité Paralímpico Internacional. 
Cuadro 1. Gobierno de los Deportes Paralímpicos. Adaptado de IPC, 2012.

\begin{tabular}{|c|c|c|c|c|}
\hline $\begin{array}{l}\text { Comité Paralímpico } \\
\text { Internacional (IPC) }\end{array}$ & $\begin{array}{l}\text { Federaciones } \\
\text { Internacionales de } \\
\text { Deportes (IF's) }\end{array}$ & \multicolumn{3}{|c|}{$\begin{array}{c}\text { Organizaciones Internaciones de Deportes para } \\
\text { Personas Discapacitadas (IOSD's) }\end{array}$} \\
\hline Esquí Alpino & Arquería (FITA) & $\begin{array}{l}\text { Asociación Internac- } \\
\text { ional de Deporte y } \\
\text { Recreación de Parálisis } \\
\text { Cerebral CPISRA }\end{array}$ & $\begin{array}{l}\text { Federación Internac- } \\
\text { ional de Deportes para } \\
\text { Ciegos - IBSA }\end{array}$ & $\begin{array}{l}\text { Federación Internac- } \\
\text { ional de Deportes para } \\
\text { Silla de Ruedas y Am- } \\
\text { putados - IWAS }\end{array}$ \\
\hline Atletismo & Ciclismo (UCI) & Boccia & Fútbol 5 & $\begin{array}{l}\text { Fencing en silla de } \\
\text { ruedas }\end{array}$ \\
\hline Biatlón & Ecuestre (FEI) & Fútbol 7 & Goalball & \\
\hline Cross Country Alpino & Para Canoe (ICF) & & Judo & \\
\hline Hockey Sobre Hielo & Remo (FISA) & & & \\
\hline $\begin{array}{l}\text { Levantamiento de } \\
\text { pesas }\end{array}$ & Navegación (IFDS) & & & \\
\hline Tiro Deportivo & Tenis de Mesa (ITTF) & & & \\
\hline Natación & Para Triatlón (ITU) & & & \\
\hline \multirow[t]{5}{*}{$\begin{array}{l}\text { Danza en silla de rue- } \\
\text { das }\end{array}$} & $\begin{array}{l}\text { Voleibol Sentado } \\
\text { (WOVD) }\end{array}$ & & & \\
\hline & $\begin{array}{l}\text { Baloncesto en Silla de } \\
\text { ruedas (IWBF) }\end{array}$ & & & \\
\hline & $\begin{array}{l}\text { Tenis en silla de Rue- } \\
\text { das (ITF) }\end{array}$ & & & \\
\hline & $\begin{array}{l}\text { Rugby en silla de rue- } \\
\text { das }\end{array}$ & & & \\
\hline & $\begin{array}{l}\text { Curling en Silla de } \\
\text { Ruedas (WCF) }\end{array}$ & & & \\
\hline
\end{tabular}

Deportes de Gobierno de las Organizaciones Internacionales de Deportes para Discapacitados - (IOSD's): Asociación Internacional de Deporte y Recreación de Parálisis Cerebral - CPISRA: Boccia y Fútbol 7. Federación Internacional de Deportes para Ciegos - IBSA: Goalball, Fútbol 5 y Judo. Federación Internacional de Deportes en Silla de Ruedas y Amputados - IWAS: Esgrima en Silla de Ruedas. Extractado del sitio web del Comité Paralímpico Internacional (2012).

Deportes de Gobierno del Comité Paralímpico Internacional - IPC: Esquí Alpino, Atletismo, Biatlón, Cross Country Alpino, Hockey sobre hielo, Levantamiento de pesas, Tiro deportivo, Natación y Danza en silla de ruedas. Extractado del sitio web del Comité Paralímpico Internacional (2012). En Colombia, la estructura del sistema Paralímpico nacio- nal (Figura 2) aun se encuentra compuesta por federaciones por discapacidad (Ministerio de Educación Nacional, decreto 641 de 2001), lo cual, obliga que cada federación por discapacidad desarrolle sus criterios por deporte, entonces encontramos que, a nivel nacional, se registren cinco criterios para el mismo deporte.

\section{ELEGIBILIDAD Y CRITERIOS DE SELECCIÓN:}

Teniendo clara la estructura del IPC y del sistema Nacional es de vital importancia presentar la normativa sobre elegibilidad y Criterios de clasificación a las Paralimpiadas - 2012, ya que ésta garantiza una competencia de alto nivel y en condiciones justas para los atletas. Es así que hasta los Juegos Paralímpicos de 1980, los deportistas que no tenían una lesión de médula espinal sólo podían participar en competiciones na- 


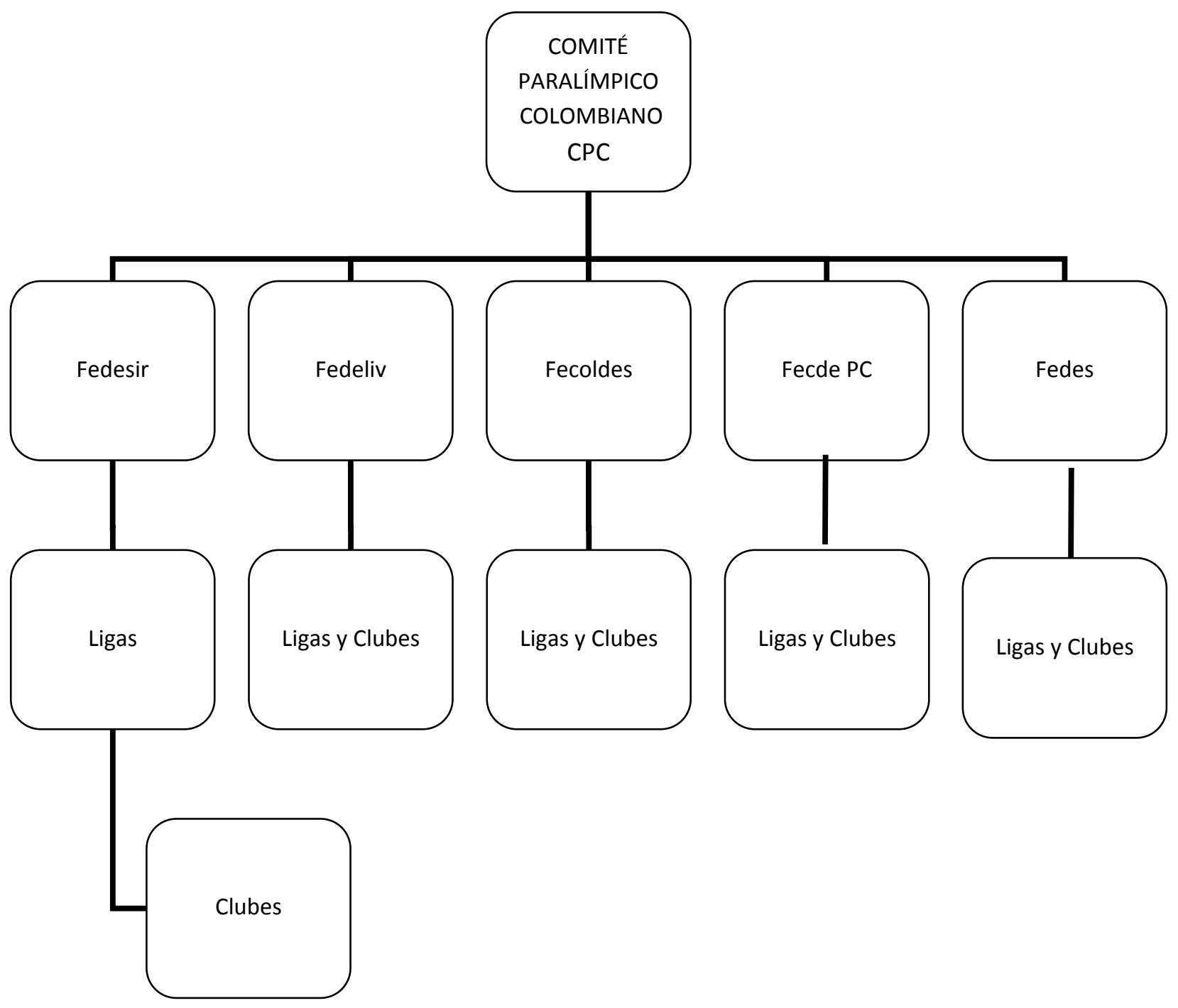

Figura 2. Estructura del Sistema Paralímpico Colombiano.

cionales, es decir, los atletas con otras discapacidades sólo podían jugar para sus equipos locales en casa y no podían representar a su país. El catalizador de este cambio fue una "clasificación funcional", que en lugar de evaluar a cada atleta en función de su discapacidad, se le evaluaba según sus habilidades potenciales restantes. Se prestó mucha atención para no penalizar a los atletas por las consecuencias de su entrenamiento y eran valorados por el potencial de motrici$\mathrm{dad} /$ movimiento que tenían a consecuencia de su discapacidad y NO por lo que no podían hacer (Sainsbury, 2004). En los procesos de obtención de cupos para las Paralimpiadas modernas, los temas de clasificación funcional han tomado el protagonismo y son parte esencial en la competencia; ra- zón, por la cual, el IPC, dentro de la estructura de criterios de clasificación, incluye eventos de obtención de cupos que además tengan en su programa espacios de clasificación funcional.

La normativa del IPC sobre elegibilidad establece las condiciones generales que se deben tener en cuenta, como prerequisito para competir en los Juegos Paralímpicos, descritos en el manual de elegibilidad, desarrollado y publicado por el IPC; de esta forma, el IPC garantiza a sus miembros las obligaciones fundamentales y salva guarda sus derechos, logrando así proteger los principios éticos y morales del movimiento paralímpico (Cuadro 2). Los comités paralímpicos 
nacionales deben dar cumplimiento a dicha normatividad $\mathrm{y}$, posteriormente, en conjunto con su equipo técnico y sus deportistas debe revisar minuciosamente los criterios por deporte, según la proyección de participación que se haya trazado el NPC. Los criterios por deporte son emitidos oficialmente por el Comité Paralímpico Internacional, elaborados según la estructura de deportes descrita en el cuadro 3 es así como cada Federación Internacional y Organización Internacional, en coordinación con el IPC, emite los criterios de clasificación para la siguiente temporada de Juegos Paralímpicos; este documento de criterios es publicado, con el objetivo de informar oportunamente a los NPC's sobre las normas generales de elegibilidad que se tendrán en cuenta para esta temporada, los Criterios de Clasificación específicos de cada deporte, los Aspectos Generales del Programa de los Juegos Paralímpicos y un Glosario con la terminología utilizada. Éste, se convierte en la carta de navegación de cada comité paralímpico nacional en su camino a la clasificación de deportistas a las Paralimpiadas.

Cuadro 2: Manual de elegibilidad 2009, adaptado del IPC.

\begin{tabular}{|c|c|}
\hline Normas de Elegibilidad & Descripción \\
\hline Calidad de Miembro del IPC & $\begin{array}{l}\text { Solo podrán inscribir deportistas para competir en los Juegos Paralímpicos de Londres } \\
2012 \text { aquellos Comités Paralímpicos Nacionales que estén al corriente de sus pagos } \\
\text { con el IPC. Al mismo tiempo, las federaciones nacionales de cada país deben estar al } \\
\text { corriente en los pagos de afiliación en los deportes de Organizaciones Internacionales } \\
\text { de Deporte para Discapacitados (IOSD's) o por Federaciones Internacionales (IF's), } \\
\text { incluyendo al IPC, durante el periodo de clasificación y hasta el cierre de la inscripción } \\
\text { para los Juegos Paralímpicos. }\end{array}$ \\
\hline $\begin{array}{l}\text { Cumplimiento del código de } \\
\text { nacionalidad de los deportis- } \\
\text { tas }\end{array}$ & $\begin{array}{l}\text { Los deportistas que participen en los Juegos Paralímpicos deben ser ciudadanos del } \\
\text { país que los inscribe en el programa de los juegos. }\end{array}$ \\
\hline Requisito de la Edad Mínima & $\begin{array}{l}\text { El Comité Paralímpico Internacional no establece un límite de edad para los deportistas } \\
\text { que compiten en los Juegos Paralímpicos; sin embargo, con referencia al tema de la } \\
\text { edad indica que los deportistas que participen en los juegos deben estar correctamente } \\
\text { preparados para la competencia internacional a nivel élite. }\end{array}$ \\
\hline $\begin{array}{l}\text { Entendimiento y Cumplimien- } \\
\text { to del Código de Elegibilidad } \\
\text { del IPC }\end{array}$ & $\begin{array}{l}\text { El código de elegibilidad es un documento donde el IPC plasma las normas generales } \\
\text { de elegibilidad; este documento es de uso de los NPC's y debe ser ampliamente expli- } \\
\text { cado a los deportistas, en el proceso de licenciamiento de deportistas deben firmar el } \\
\text { formato de elegibilidad donde confirman que comprenden y acatan estas normas. }\end{array}$ \\
\hline Normas de Selección del NPC & $\begin{array}{l}\text { El Comité Paralímpico Internacional - IPC reconoce y respeta el derecho de los Com- } \\
\text { ités Paralímpicos Nacionales - NPC's a establecer las normas de selección nacionales } \\
\text { que determinen la clasificación de un deportista o equipo para competir en los Juegos } \\
\text { Paralímpicos; sin embargo, estos criterios deben estar en cumplimiento con el articulo } \\
\text { 2.2.6 de la Normativa Interna del IPC "los Derechos y Obligaciones de los Miembros de } \\
\text { IPC" y respetar los términos sobre fechas de confirmación y clasificación plasmados en } \\
\text { los criterios de clasificación de cada deporte. }\end{array}$ \\
\hline $\begin{array}{l}\text { Cumplimiento del Reglamen- } \\
\text { to de Clasificación Médico - } \\
\text { Funcional }\end{array}$ & $\begin{array}{l}\text { Sólo serán elegibles para su inscripción en los Juegos Paralímpicos de Londres } 2012 \\
\text { aquellos deportistas clasificados que cumplan las condiciones de clasificación médico- } \\
\text { funcional específicas de su deporte y tengan el estatus de clasificación deportiva indi- } \\
\text { cado en los criterios de elegibilidad del deportista específicos del deporte. Es responsa- } \\
\text { bilidad de cada Comité Paralímpico Nacional asegurar que todos sus deportistas están } \\
\text { debidamente clasificados en los respectivos deportes, antes de proceder a la inscrip- } \\
\text { ción. }\end{array}$ \\
\hline
\end{tabular}


Teniendo en cuenta que las normas de elegibilidad ya fueron abordadas, se enunciarán los criterios de clasificación por deporte a los juegos paralímpicos de Londres 2012 (Cua- dro 3). Las plazas no utilizadas o no confirmadas por ningún NPC son reasignadas, a través de diversos métodos de asignación (Cuadro 4).

Cuadro 3. Métodos de clasificación por deporte. Adaptado de: Criterios de Clasificación a Londres 2012, versión diciembre 2011.

\begin{tabular}{|c|c|c|c|}
\hline \# & DEPORTE & MÉTODO DE CLASIFICACIÓN & RESUMEN DESCRIPCIÓN DEL MÉTODO \\
\hline \multirow[t]{4}{*}{1} & \multirow[t]{4}{*}{$\begin{array}{l}\text { ATLETIS- } \\
\text { MO }\end{array}$} & $\begin{array}{l}\text { Asignación por los Campeona- } \\
\text { tos del Mundo de Atletismo del } \\
\text { IPC } 2011\end{array}$ & $\begin{array}{l}\text { Se refiere a la obtención de cupos, según la ubicación final del } \\
\text { deportista en pruebas determinadas, para este caso solo obtienen } \\
\text { cupo para el NPC los deportistas que ocupen primero y segundo } \\
\text { lugar en las pruebas individuales con medalla en el Programa de } \\
\text { los Juegos Paralímpicos. }\end{array}$ \\
\hline & & $\begin{array}{l}\text { Asignación directa por Marca } \\
\text { Mínima de nivel "A" (AQS) }\end{array}$ & $\begin{array}{l}\text { A través de éste método, se podrán asignar a cada NPC una plaza } \\
\text { de clasificación por cada uno de los deportistas elegibles de ese } \\
\text { NPC que haya alcanzado una AQS. Este método cuenta con dos } \\
\text { fases de ejecución: en la primera, se asignarán el } 60 \% \text { de las plazas } \\
\text { existentes y se tomará en cuenta la recolección de marcas realiza- } \\
\text { das entre el } 1 \text { de diciembre de } 2010 \text { y el } 31 \text { de diciembre de } 2011 \text {. } \\
\text { En la segunda fase, se asignan el porcentaje de plazas restantes } \\
\text { con base en los resultados recogidos de competiciones reconoci- } \\
\text { das por el IPC, celebradas entre el } 1 \text { de enero de } 2012 \text { y el } 20 \text { de } \\
\text { mayo de } 2012 \text {. En el caso que el número de deportistas con AQS } \\
\text { sea mayor que el número de cupos asignados en cada fase, el IPC } \\
\text { asignará las plazas restantes, bajo fórmula descrita en los criterios. }\end{array}$ \\
\hline & & $\begin{array}{l}\text { Asignación por Marca Mínima } \\
\text { de nivel "B" (BQS) }\end{array}$ & $\begin{array}{l}\text { El Método de Asignación por BQS sólo será utilizado si hay plazas } \\
\text { de clasificación sobrantes del Método de Asignación Directa por } \\
\text { AQS. }\end{array}$ \\
\hline & & $\begin{array}{l}\text { Asignación } \\
\text { por Invitación de la Comisión } \\
\text { Bipartita }\end{array}$ & $\begin{array}{l}\text { A través de los criterios, se asigna un número de invitaciones to- } \\
\text { tales disponibles en masculino y femenino; al mismo tiempo, los } \\
\text { NPC's deben enviar sus solicitudes de invitación al IPC Atletismo. }\end{array}$ \\
\hline \multirow[t]{3}{*}{2} & \multirow[t]{3}{*}{ CICLISMO } & $\begin{array}{l}\text { Asignación por el Ranking por } \\
\text { Naciones "Combinado" de Pista } \\
\text { y Carretera de Juegos de Ciclis- } \\
\text { mo Paralímpico UCI a fecha } 31 \\
\text { de diciembre de } 2010\end{array}$ & $\begin{array}{l}\text { Se asignará una plaza Masculina a los } 40 \text { NPC's con puntos en la } \\
\text { lista de ranking por países. Se asigna una plaza Femenina a los } 25 \\
\text { NPC's con puntos en la lista de ranking por nacionales, combinado } \\
\text { pista y ruta. }\end{array}$ \\
\hline & & $\begin{array}{l}\text { Asignación por el Ranking por } \\
\text { Naciones "Combinado" de Pista } \\
\text { y Carretera de Juegos de Ciclis- } \\
\text { mo Paralímpico UCI a fecha } 13 \\
\text { de febrero de } 2012\end{array}$ & $\begin{array}{l}\text { Será determinado sumando los puntos de ranking de todas las na- } \\
\text { ciones y dividiéndolo por el factor descrito en los criterios por de- } \\
\text { porte, esto aplicará para las pruebas desarrolladas en los campeo- } \\
\text { natos oficiales; esta fórmula será aplicada para el género femenino } \\
\text { y masculino cada uno con su factor correspondiente y diferente. }\end{array}$ \\
\hline & & $\begin{array}{l}\text { Asignación por Invitación de la } \\
\text { Comisión Bipartita }\end{array}$ & $\begin{array}{l}\text { A través de los criterios, se asigna un número de invitaciones to- } \\
\text { tales disponibles en masculino y femenino; al mismo tiempo, los } \\
\text { NPC's deben enviar sus solicitudes de invitación a la UCI. }\end{array}$ \\
\hline
\end{tabular}


Continuación cuadro 3.

\begin{tabular}{|c|c|c|c|}
\hline \multirow[t]{3}{*}{3} & \multirow[t]{3}{*}{ NATACIÓN } & $\begin{array}{l}\text { Asignación } \\
\text { por los Campeonatos del Mundo } \\
\text { de Natación del IPC } 2010\end{array}$ & $\begin{array}{l}\text { Se refiere a la obtención de cupos según la ubicación final del de- } \\
\text { portista en pruebas determinadas, para este caso solo obtienen } \\
\text { cupo para el NPC los dos primeros deportistas clasificados en las } \\
\text { pruebas individuales, con medalla en el Programa de los Juegos } \\
\text { Paralímpicos. }\end{array}$ \\
\hline & & $\begin{array}{l}\text { Asignación por Marca Mínima } \\
\text { de Clasificación (MQS) }\end{array}$ & 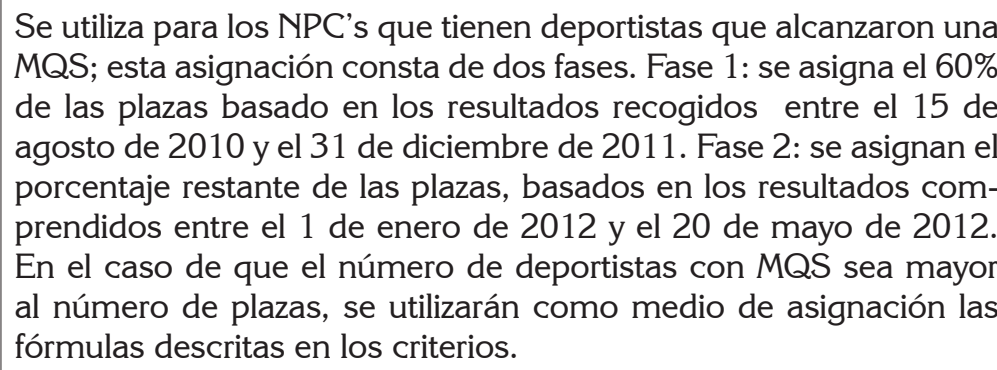 \\
\hline & & $\begin{array}{l}\text { Asignación por Invitación de la } \\
\text { Comisión Bipartita }\end{array}$ & $\begin{array}{l}\text { A través de los criterios, se asigna un número de invitaciones to- } \\
\text { tales disponibles en masculino y femenino; al mismo tiempo, los } \\
\text { NPC's deben enviar sus solicitudes de invitación al IPC Natación }\end{array}$ \\
\hline \multirow[t]{6}{*}{4} & \multirow{6}{*}{$\begin{array}{l}\text { ESGRIMA } \\
\text { EN SILLA } \\
\text { DE RUE- } \\
\text { DAS }\end{array}$} & $\begin{array}{l}\text { Asignación por los Campeona- } \\
\text { tos del Mundo de Esgrima en } \\
\text { Silla de Ruedas de IWAS } 2010\end{array}$ & $\begin{array}{l}\text { Se clasifica el deportista ubicado primero en el ranking de cada } \\
\text { prueba, aplica para hombres y mujeres. }\end{array}$ \\
\hline & & $\begin{array}{l}\text { Asignación por los Campeona- } \\
\text { tos del Mundo de Esgrima en } \\
\text { Silla de Ruedas de IWAS } 2011\end{array}$ & $\begin{array}{l}\text { Se clasifica el deportista ubicado primero en el ranking de cada } \\
\text { prueba, aplica para hombres y mujeres. }\end{array}$ \\
\hline & & $\begin{array}{l}\text { Asignación por los Campeona- } \\
\text { tos Regionales de Esgrima en } \\
\text { Silla de Ruedas de IWAS } 2011\end{array}$ & $\begin{array}{l}\text { Se clasifica el tirador ubicado en la posición número } 1 \text { de los cam- } \\
\text { peonatos regionales de Asia, América y Europa. En caso que no se } \\
\text { realicen los campeonatos regionales, se asignarán según el ranking } \\
\text { Mundial de Esgrima en Silla de ruedas de IWAS. }\end{array}$ \\
\hline & & $\begin{array}{l}\text { Asignación por la Lista del Rank- } \\
\text { ing Mundial de Esgrima en Silla } \\
\text { de Ruedas }\end{array}$ & $\begin{array}{l}\text { Clasifican los tiradores ubicados en los primeros puestos de cada } \\
\text { prueba, según el ranking mundial de esgrima en silla de ruedas. }\end{array}$ \\
\hline & & Asignación al País Anfitrión & $\begin{array}{l}\text { El país anfitrión recibe directamente dos plazas de clasificación, } \\
\text { una femenina y otra masculina. }\end{array}$ \\
\hline & & $\begin{array}{l}\text { Asignación por Invitación de la } \\
\text { Comisión Bipartita }\end{array}$ & $\begin{array}{l}\text { A través de los criterios, se asigna un número de invitaciones to- } \\
\text { tales disponibles en masculino y femenino; al mismo tiempo, los } \\
\text { NPC's deben enviar sus solicitudes de invitación al IPC Natación }\end{array}$ \\
\hline
\end{tabular}


Continuación cuadro 3.

\begin{tabular}{|c|c|c|c|}
\hline \multirow[t]{4}{*}{5} & \multirow[t]{4}{*}{$\begin{array}{l}\text { TIRO CON } \\
\text { ARCO }\end{array}$} & Asignación al País Anfitrión & $\begin{array}{l}\text { Si el país anfitrión clasifica a tres deportistas o menos, la federación } \\
\text { internacional le asignará plazas de clasificación, para formar equi- } \\
\text { pos en masculino o femenino }\end{array}$ \\
\hline & & $\begin{array}{l}\text { Asignación por los Campeona- } \\
\text { tos del Mundo de Tiro con Arco } \\
\text { al Aire Libre FITA } 2011\end{array}$ & $\begin{array}{l}\text { Otorga clasificación por equipos e individual. En el caso de la asig- } \\
\text { nación por equipos en la modalidad de tiro recurvo masculino, se } \\
\text { clasifican los } 6 \text { primeros equipos; en el caso del género femenino, } \\
\text { clasifican los primeros cuatro equipos. En la clasificación individual } \\
\text { clasifican para una plaza los deportistas que no se hayan clasificado } \\
\text { por el método de equipos y que estén ubicados en los tres primeros } \\
\text { lugares de las pruebas ofrecidas en el programa de los Juegos. }\end{array}$ \\
\hline & & $\begin{array}{l}\text { Asignación por los Campeona- } \\
\text { tos Regionales de Tiro con Arco } \\
\text { FITA 2010/2011 }\end{array}$ & $\begin{array}{l}\text { Se clasifica el deportista ubicado primero en los juegos regionales } \\
\text { de América, Asia y Europa en las pruebas individuales ofrecidas } \\
\text { en el programa de las paralimpiadas, aplica para las pruebas de } \\
\text { hombres y de mujeres. }\end{array}$ \\
\hline & & $\begin{array}{l}\text { Asignación por el Torneo de } \\
\text { Clasificación de Tiro con Arco } \\
\text { Paralímpico FITA }\end{array}$ & $\begin{array}{l}\text { Se clasifican los deportistas masculino y femenino, clasificados } \\
\text { primeros, que no hayan conseguido clasificación por ningún otro } \\
\text { método. }\end{array}$ \\
\hline \multirow[t]{3}{*}{6} & \multirow[t]{3}{*}{$\begin{array}{l}\text { TENIS DE } \\
\text { MESA }\end{array}$} & $\begin{array}{l}\text { Asignación por los Campeona- } \\
\text { tos Regionales de Tenis de Mesa } \\
\text { Paralímpico de la ITTF } 2011\end{array}$ & $\begin{array}{l}\text { Se clasifica el jugador ubicado en la primera posición de ranking } \\
\text { en cada prueba individual; para los campeonatos regionales de: } \\
\text { América, África, Asia y Europa. Esto para femenino y masculino. }\end{array}$ \\
\hline & & $\begin{array}{l}\text { Asignación por las Listas del } \\
\text { Ranking Mundial Masculino y } \\
\text { Femenino de Tenis de Mesa Par- } \\
\text { alímpico de la ITTF }\end{array}$ & $\begin{array}{l}\text { Se clasifican los jugadores que no se hayan clasificado por otro } \\
\text { medio, ubicados en los primeros lugares del Ranking Mundial de } \\
\text { la ITTF, hasta completar el cupo de la prueba individual. }\end{array}$ \\
\hline & & $\begin{array}{l}\text { Asignación por Invitación de la } \\
\text { Comisión Bipartita }\end{array}$ & $\begin{array}{l}\text { La ITTF y el IPC asignarán las invitaciones por invitación Bipartita } \\
\text { hasta completar los cupos disponibles por clase. }\end{array}$ \\
\hline \multirow[t]{5}{*}{7} & \multirow[t]{5}{*}{ TIRO } & $\begin{array}{l}\text { Asignación Directa por los } \\
\text { Campeonatos del Mundo de } \\
\text { Tiro Olímpico de IPC } 2010\end{array}$ & $\begin{array}{l}\text { Los dos primeros deportistas de cada prueba convocada en el pro- } \\
\text { grama de los juegos consiguen un cupo para su NPC. }\end{array}$ \\
\hline & & $\begin{array}{l}\text { Asignación Directa por los } \\
\text { Campeonatos Regionales de } \\
\text { Tiro Olímpico de IPC }\end{array}$ & $\begin{array}{l}\text { Se asignarán } 12 \text { plazas de clasificación a los siguientes campeona- } \\
\text { tos regionales: Asia 2009, Asia } 2011 \text { y Europa } 2011\end{array}$ \\
\hline & & $\begin{array}{l}\text { Asignación por las Listas de } \\
\text { Clasificación de } M Q S \text { de Tiro } \\
\text { Olímpico del IPC }\end{array}$ & $\begin{array}{l}\text { Se realizará una lista con los deportistas que realizaron la MQS } \\
\text { desde el año } 2009 \text { hasta } 2011 \text { en los campeonatos oficiales del } \\
\text { IPC; posteriormente, bajo fórmula especificada en los criterios, se } \\
\text { asignarán las plazas a cada NPC con deportistas elegibles por este } \\
\text { método }\end{array}$ \\
\hline & & $\begin{array}{l}\text { Asignación (MQS) por Campe- } \\
\text { onatos del Mundo, Campeona- } \\
\text { tos Regionales, y Copas del } \\
\text { Mundo de Tiro Olímpico del IPC }\end{array}$ & $\begin{array}{l}\text { Un deportista para ser incluido en la lista final de clasificación debe- } \\
\text { rá haber obtenido } 2 \text { resultados de MQS; luego, mediante fórmula } \\
\text { especificada en los criterios, se asignarán las plazas para hombres } \\
\text { y mujeres. }\end{array}$ \\
\hline & & $\begin{array}{l}\text { Asignación por Invitación de la } \\
\text { Comisión Bipartita }\end{array}$ & $\begin{array}{l}\text { Solo se asignarán cuatro invitaciones de comisión bipartita, los } \\
\text { NPC's deben solicitar al IPC la asignación de invitación bipartita. }\end{array}$ \\
\hline
\end{tabular}


Continuación cuadro 3 .

\begin{tabular}{|c|c|c|c|}
\hline \multirow[t]{3}{*}{8} & \multirow[t]{3}{*}{ BOCCIA } & $\begin{array}{l}\text { Asignación por las Listas del } \\
\text { Ranking de Clasificación Par- } \\
\text { alímpica de Parejas y Equipos } \\
\text { de Boccia de CP-ISRA }\end{array}$ & $\begin{array}{l}\text { Basados en las Listas de Ranking Mundial de la CPISRA para las } \\
\text { modalidades de Parejas y equipos en cada una de las clasificacio- } \\
\text { nes existentes, se clasificarán los } 11 \text { primeros para las clasificacio- } \\
\text { nes BC1 /BC2 y los siete primeros para BC3 y BC4, hasta comple- } \\
\text { tar el número máximo de deportistas. }\end{array}$ \\
\hline & & $\begin{array}{l}\text { Asignación por las Listas del } \\
\text { Ranking Mundial Individual de } \\
\text { Boccia de CP-ISRA }\end{array}$ & $\begin{array}{l}\text { Después de la asignación por parejas y equipos, la CPISRA podrá } \\
\text { asignar cupos según las lista de ranking Mundial Individual a los } \\
\text { deportistas que se encuentren ubicados en los primeros lugares } \\
\text { del ranking. }\end{array}$ \\
\hline & & Asignación al País Anfitrión & $\begin{array}{l}\text { Se clasificará un equipo } \mathrm{BC} 1 / \mathrm{BC} 2 \text { una pareja } \mathrm{BC} 3 \text { y una pareja } \\
\mathrm{BC} 4 \text {. Esto sujeto a encontrarse en la lista de Ranking Mundial de } \\
\text { la CPISRA }\end{array}$ \\
\hline \multirow[t]{2}{*}{9} & \multirow[t]{2}{*}{ FÚTBOL 5} & $\begin{array}{l}\text { Asignación por los Campeona- } \\
\text { tos del Mundo de Fútbol - } 5 \text { de } \\
\text { IBSA } 2010\end{array}$ & Se clasifica el NPC ubicado en el lugar $\mathrm{N}^{\circ} 1$ \\
\hline & & $\begin{array}{l}\text { Asignación por los Campeona- } \\
\text { tos Regionales de Fútbol - } 5 \text { de } \\
\text { IBSA 2010/2011 }\end{array}$ & $\begin{array}{l}\text { Para los campeonatos regionales de Asia, se clasifica NPC ubicado } \\
\text { en el primer lugar; en los campeonatos de Europa y de la IBSA } \\
2011 \text {, se clasifica primer y segundo lugar; para la región de Améri- } \\
\text { ca, se clasifican los NPC ubicados Primero y segundo lugar; para la } \\
\text { región de África, se clasificará el NPC mejor ubicado en el clasifica- } \\
\text { torio regional de la IBSA } 2011 \text {. }\end{array}$ \\
\hline \multirow[t]{4}{*}{10} & \multirow[t]{4}{*}{ REMO } & $\begin{array}{l}\text { Asignación por los Campeona- } \\
\text { tos del Mundo de Remo } 2011\end{array}$ & $\begin{array}{l}\text { Se clasifican las primeras ocho embarcaciones registradas en las } \\
\text { pruebas ofrecidas en el programa de Remo de los Juegos Paralím- } \\
\text { picos }\end{array}$ \\
\hline & & $\begin{array}{l}\text { Asignación por la Regata Final } \\
\text { de Clasificación Paralímpica } \\
2012\end{array}$ & $\begin{array}{l}\text { Se clasifican los dos primeros lugares de: Single Sculls Masculino } \\
\text { AS - ASM1x, Single Sculls Femenino AS - ASW1x, Doble Sculls } \\
\text { Mixto TA - TAMix2x, y Cuatros con Timonel - LTAMix4+. Y los tres } \\
\text { primeros lugares de Cuatros Mixto con Timonel ID - IDMix4+ }\end{array}$ \\
\hline & & Asignación al País Anfitrión & $\begin{array}{l}\text { En caso que le país anfitrión no haya clasificado por ninguno de los } \\
\text { métodos anteriores, la FISA otorgará plazas de participación en las } \\
\text { pruebas que se encuentre mejor ubicado. }\end{array}$ \\
\hline & & $\begin{array}{l}\text { Asignación por Invitación de la } \\
\text { Comisión Bipartita }\end{array}$ & $\begin{array}{l}\text { La FISA y el IPC ya han asignado un número máximo total de in- } \\
\text { vitaciones por comisión bipartita, los NPC's que requieran utilizar } \\
\text { este método deben hacer llegar la respectiva solicitud a la FISA. }\end{array}$ \\
\hline \multirow[t]{4}{*}{11} & \multirow[t]{4}{*}{ ECUESTRE } & $\begin{array}{l}\text { Campeonatos del Mundo de } \\
\text { Hípica para Discapacitados de la } \\
\text { FEI } 2010\end{array}$ & $\begin{array}{l}\text { Los tres primeros equipos clasificados recibirán cinco plazas de } \\
\text { clasificación. }\end{array}$ \\
\hline & & $\begin{array}{l}\text { Asignación por el Ranking por } \\
\text { Equipos de Hípica Paralímpica }\end{array}$ & $\begin{array}{l}\text { El equipo en el primer lugar del ranking por equipos de la FEI, } \\
\text { no clasificado por otro método se le otorgarán cinco plazas. En la } \\
\text { distribución general por regiones serán otorgadas cuatro plazas a } \\
\text { uno de los NPC de las regiones de Asia, América, África y Oceanía; } \\
\text { según la lista de ranking por equipos de la FEI. }\end{array}$ \\
\hline & & $\begin{array}{l}\text { Asignación por el Ranking Indi- } \\
\text { vidual de Hípica Paralímpica }\end{array}$ & $\begin{array}{l}\text { Solo son elegibles para la asignación de plazas por este método } \\
\text { los NPC's que no hayan conseguido plazas de clasificación con los } \\
\text { métodos anteriores. Dos plazas de asignación para cada región, en } \\
\text { el caso de las regiones. }\end{array}$ \\
\hline & & $\begin{array}{l}\text { Asignación por Invitación de la } \\
\text { Comisión Bipartita }\end{array}$ & $\begin{array}{l}\text { A través de los criterios, se asigna un número de invitaciones to- } \\
\text { tales disponibles en masculino y femenino; al mismo tiempo, los } \\
\text { NPC's deben enviar sus solicitudes de invitación a FEI. }\end{array}$ \\
\hline
\end{tabular}


Continuación cuadro 3.

\begin{tabular}{|c|c|c|c|}
\hline \multirow[t]{3}{*}{12} & \multirow[t]{3}{*}{ VELA } & $\begin{array}{l}\text { Asignación por los Campeona- } \\
\text { tos del Mundo de Vela para Dis- } \\
\text { capacitados de la IFDS } 2010\end{array}$ & $\begin{array}{l}\text { En } 2.4 \mathrm{mR} \text { (Embarcación de } 1 \text { Persona), se clasifican los siete pri- } \\
\text { meros países. En SKUD18 (Embarcación de dos Personas), seis } \\
\text { primeros países. En Sonar (Embarcación de tres Personas), siete } \\
\text { primeros países. }\end{array}$ \\
\hline & & $\begin{array}{l}\text { Asignación por los Campeona- } \\
\text { tos del Mundo de Vela para Dis- } \\
\text { capacitados de la IFDS } 2011\end{array}$ & $\begin{array}{l}\text { En } 2.4 \mathrm{mR} \text { (Embarcación de una persona), se clasifican los seis pri- } \\
\text { meros países. En SKUD18 (Embarcación de dos Personas), cinco } \\
\text { primeros países. En Sonar (Embarcación de tres Personas), seis } \\
\text { primeros países. }\end{array}$ \\
\hline & & Asignación al País Anfitrión & $\begin{array}{l}\text { En } 2.4 \mathrm{mR} \text { (Embarcación de una Persona), se otorga una plaza de } \\
\text { clasificación, dos plazas de clasificación en SKUD18 (Embarcación } \\
\text { de dos Personas). En Sonar (Embarcación de tres Personas), se } \\
\text { otorgarán tres plazas de clasificación directa. }\end{array}$ \\
\hline \multirow[t]{3}{*}{13} & \multirow[t]{3}{*}{$\begin{array}{l}\text { TENIS EN } \\
\text { SILLA DE } \\
\text { RUEDAS }\end{array}$} & $\begin{array}{l}\text { Asignación por el Ranking Mun- } \\
\text { dial en Individuales de Tenis en } \\
\text { Silla de Ruedas de la ITF }\end{array}$ & $\begin{array}{l}\text { Se clasifican los jugadores hombres que se encuentren ubicados } \\
\text { dentro de los primeros } 46 \text { del ranking de la ITF individuales. Se } \\
\text { clasifican las Mujeres que se encuentren ubicadas en las primeros } \\
22 \text { puestos del Ranking individual femenino de la ITF. Se clasifican } \\
\text { los doce (12) primeros jugadores quad clasificados en el Ranking } \\
\text { Mundial en individuales de Tenis en Silla de Ruedas de la ITF. Para } \\
\text { el caso de este método de clasificación, el cierre del ranking es el } \\
21 \text { de mayo de } 2012 \text {. }\end{array}$ \\
\hline & & $\begin{array}{l}\text { Juegos Regionales de Tenis en } \\
\text { Silla de Ruedas de la ITF }\end{array}$ & $\begin{array}{l}\text { Para cada uno de los Juegos asiáticos y americanos se otorgará } \\
\text { una plaza de clasificación para hombres y otra para mujeres. }\end{array}$ \\
\hline & & $\begin{array}{l}\text { Asignación por Invitación de la } \\
\text { Comisión Bipartita }\end{array}$ & $\begin{array}{l}\text { A través de los criterios, se asigna un número de invitaciones tota- } \\
\text { les disponibles en masculino, femenino y que al mismo tiempo los } \\
\text { NPC's deben enviar sus solicitudes de invitación a la ITF y el IPC. }\end{array}$ \\
\hline \multirow[t]{2}{*}{14} & \multirow[t]{2}{*}{$\begin{array}{l}\text { LEVANTA- } \\
\text { MIENTO } \\
\text { PESAS }\end{array}$} & $\begin{array}{l}\text { Asignación por la lista de Marcas } \\
\text { Mínimas de Clasificación (MQS) }\end{array}$ & $\begin{array}{l}\text { Se asignan plazas de clasificación en cada una de las modalidades } \\
\text { a los diez primeros deportistas hombres y las } 6 \text { deportistas mujeres } \\
\text { registrados en la lista de MQS de Levantamiento de Pesas. }\end{array}$ \\
\hline & & $\begin{array}{l}\text { Asignación por Invitación de la } \\
\text { Comisión Bipartita }\end{array}$ & $\begin{array}{l}\text { A través de los criterios, se asigna un número de invitaciones tota- } \\
\text { les en masculino y femenino que se encuentran estipuladas en los } \\
\text { criterios de este deporte; al mismo tiempo, los NPC's deben enviar } \\
\text { sus solicitudes de invitación a IPC Powerlifting. }\end{array}$ \\
\hline \multirow[t]{3}{*}{15} & \multirow[t]{3}{*}{ GOALBALL } & $\begin{array}{l}\text { Asignación por los Campeona- } \\
\text { tos del Mundo de Goalball de } \\
\text { IBSA } 2010\end{array}$ & $\begin{array}{l}\text { Se clasifican los NPC's ubicados en los tres primeros lugares de la } \\
\text { categoría masculino y femenino, esto se ajustara con los resultados } \\
\text { de los campeonatos de la IBSA del } 2011\end{array}$ \\
\hline & & $\begin{array}{l}\text { Asignación por el Torneo Par- } \\
\text { alímpico de Clasificación de } \\
\text { Goalball de IBSA } 2011\end{array}$ & $\begin{array}{l}\text { Se clasifican los NPC's ubicados en los primeros cuatro lugares en } \\
\text { las categorías masculino y femenino. }\end{array}$ \\
\hline & & Asignación al País Anfitrión & $\begin{array}{l}\text { El país anfitrión recibe directamente dos plazas de clasificación: } \\
\text { una femenina y otra masculina. }\end{array}$ \\
\hline \multirow[t]{2}{*}{16} & \multirow[t]{2}{*}{$\begin{array}{l}\text { BALON- } \\
\text { CESTO EN } \\
\text { SILLA DE } \\
\text { RUEDAS }\end{array}$} & $\begin{array}{l}\text { Asignación por los Campe- } \\
\text { onatos Zonales de Baloncesto } \\
\text { en Silla de Ruedas de la IWBF } \\
2010 / 2011\end{array}$ & $\begin{array}{l}\text { Se clasifica el NPC que consiga el primer lugar en los campeonatos } \\
\text { zonales de: África, América, Asia - Oceanía, y Europa. Aplica para } \\
\text { los campeonatos de } 2010 \text { y } 2011 \text {. }\end{array}$ \\
\hline & & Asignación al País Anfitrión & $\begin{array}{l}\text { El país anfitrión clasifica directamente un equipo masculino y un } \\
\text { esquipo femenino. }\end{array}$ \\
\hline
\end{tabular}


Continuación cuadro 3.

\begin{tabular}{|c|c|c|c|}
\hline \multirow[t]{3}{*}{17} & \multirow[t]{3}{*}{ JUDO } & $\begin{array}{l}\text { Asignación por el Ranking Mun- } \\
\text { dial de Judo de IBSA }\end{array}$ & $\begin{array}{l}\text { Se clasifican los deportistas hombres ubicados dentro de los diez } \\
\text { primeros lugares del ranking mundial de la IBSA por categoría de } \\
\text { peso al cierre estipulado en los criterios del deporte. Se clasifican } \\
\text { las mujeres deportistas ubicadas dentro de los } 6 \text { primeros lugares } \\
\text { del ranking de la IBSA al cierre estipulado en los criterios. }\end{array}$ \\
\hline & & Asignación al País Anfitrión & $\begin{array}{l}\text { El país anfitrión clasifica directamente un deportista en cada cate- } \\
\text { goría de peso para ambos sexos. }\end{array}$ \\
\hline & & $\begin{array}{l}\text { Asignación por Invitación de la } \\
\text { Comisión Bipartita }\end{array}$ & $\begin{array}{l}\text { A través de los criterios, se asigna un número de invitaciones tota- } \\
\text { les en masculino y femenino, que se encuentran estipuladas en los } \\
\text { criterios de este deporte; al mismo tiempo, los NPC's deben enviar } \\
\text { sus solicitudes de invitación a la IBSA y al IPC. }\end{array}$ \\
\hline \multirow[t]{3}{*}{18} & \multirow[t]{3}{*}{ FÚTBOL 7} & $\begin{array}{l}\text { Asignación por el Torneo Re- } \\
\text { gional Clasificador de Fútbol-7 } \\
\text { de CP-ISRA } 2010\end{array}$ & $\begin{array}{l}\text { El NPC que ocupe el mejor lugar en los campeonatos regionales de } \\
\text { Asia, América y Europa. }\end{array}$ \\
\hline & & $\begin{array}{l}\text { Asignación por los Campeona- } \\
\text { tos del Mundo de Fútbol-7 de } \\
\text { CP-ISRA } 2011\end{array}$ & $\begin{array}{l}\text { Se clasifican los cuatro Comités Paralímpicos Nacionales del tor- } \\
\text { neo masculino, que no hayan obtenido una plaza de clasificación } \\
\text { por otro método. }\end{array}$ \\
\hline & & Asignación al País Anfitrión & El país anfitrión clasifica directamente un equipo masculino. \\
\hline \multirow[t]{4}{*}{19} & \multirow[t]{4}{*}{$\begin{array}{l}\text { VOLEY- } \\
\text { BALL } \\
\text { SENTADO }\end{array}$} & $\begin{array}{l}\text { Asignacion por los Campeona- } \\
\text { tos del Mundo de Voleibol sen- } \\
\text { tado de la WOVD } 2010\end{array}$ & $\begin{array}{l}\text { Se otorgará cupo a los equipos clasificados en los tres primeros } \\
\text { lugares de la categoría masculina. Se otorgará cupo a los equipos } \\
\text { clasificados en los tres primeros lugares de la categoría femenina. }\end{array}$ \\
\hline & & $\begin{array}{l}\text { Asignación por los campeona- } \\
\text { tos regionales realizados en el } \\
\text { 2010/2011de Voleibol Sentado } \\
\text { de la WOVD }\end{array}$ & $\begin{array}{l}\text { El Comité Paralímpico Nacional en la rama masculina ubicado en } \\
\text { el mejor lugar de los campeonatos } 2010 / 2011 \text { de la WOVD en los } \\
\text { campeonatos zonales, y que no hayan adquirido cupo a través de } \\
\text { otro método, se clasificarán así: Zona Panamericana, un equipo; } \\
\text { zona Asia-Oceanía, un equipo; zona Europea, un cupo. } \\
\text { El Comité Paralímpico Nacional en la rama masculina ubicado en } \\
\text { el mejor lugar de los campeonatos } 2010 / 2011 \text { de la WOVD en los } \\
\text { campeonatos Sub-Zonales, que no hayan adquirido cupo a través } \\
\text { de otro método, se clasificarán así: Norte de Africa - Sub zona, un } \\
\text { equipo; Sub-Saharan - Sub zona, un equipo. } \\
\text { El Comité Paralímpico Nacional en la rama femenina ubicado en } \\
\text { el mejor lugar de los campeonatos } 2010 / 2011 \text { de la WOVD en los } \\
\text { campeonatos zonales, y que no hayan adquirido cupo a través de } \\
\text { otro método, se clasificarán así: Zona Panamericana, un equipo; } \\
\text { zona Asia-Oceanía, un equipo; zona Europea, un cupo. } \\
\text { Si la zona o sub-zona no garantiza un campeonato, las plazas de } \\
\text { clasificación pueden ser re-distribuidas por el Comité Paralímpico } \\
\text { Internacional y la comisión bipartita dela WOVD. }\end{array}$ \\
\hline & & $\begin{array}{l}\text { Asignación por el campeonato } \\
\text { Intercontinental de Voleibol sen- } \\
\text { tado de la WOVD } 2012\end{array}$ & $\begin{array}{l}\text { El comité Paralímpico Nacional en la rama masculina ubicado en } \\
\text { el mejor lugar y que no haya clasificado a través de otro método } \\
\text { obtendrá un cupo. }\end{array}$ \\
\hline & & Asignación al país anfitrión & $\begin{array}{l}\text { El país anfitrión clasifica directamente un equipo masculino y un fe- } \\
\text { menino, esto sujeto a la participación en los campeonatos zonales } \\
\text { 2010/2011 de la WOVD }\end{array}$ \\
\hline
\end{tabular}


Continuación cuadro 3.

\begin{tabular}{|c|c|c|c|}
\hline \multirow[t]{3}{*}{20} & \multirow{3}{*}{$\begin{array}{l}\text { RUGBY EN } \\
\text { SILLA DE } \\
\text { RUEDAS }\end{array}$} & $\begin{array}{l}\text { Asignación por el campeonato } \\
\text { del Mundo } 2010\end{array}$ & El Comité Paralímpico mejor ubicado clasifica \\
\hline & & $\begin{array}{l}\text { Asignación por el campeonato } \\
\text { zonal } 2011\end{array}$ & $\begin{array}{l}\text { El Comité Paralímpico mejor ubicado en el campeonato zonal de } \\
\text { América clasifica. } \\
\text { Los dos comités paralímpicos nacionales mejor ubicados en el } \\
\text { campeonato zonal de Europa se clasifican. } \\
\text { El comité paralímpico mejor ubicado en el campeonato zonal de } \\
\text { Oceanía se clasifica. }\end{array}$ \\
\hline & & $\begin{array}{l}\text { Asignación por el ranking Mun- } \\
\text { dial de Rugby en Silla de ruedas } \\
\text { IWRF }\end{array}$ & $\begin{array}{l}\text { Los Comités Paralímpicos Nacionales ubicados en los dos prime- } \\
\text { ros lugares del ranking mundial de rugby en silla de ruedas al cierre } \\
\text { del } 31 \text { de Enero de } 2012 \text { y que no haya sido clasificado a través de } \\
\text { otro método, se clasifican. }\end{array}$ \\
\hline
\end{tabular}

De esta manera, el Comité Paralímpico Internacional, en conjunto con las Federaciones Internacionales por deporte y las organizaciones internacionales de deportes para discapacitados, informan a los comités paralímpicos nacionales, regionales y a los deportistas la forma de clasificación y obtención de cupos a las Paralimpiadas 2012; el Comité Paralímpico Internacional ha procurado que esta estructura de criterios técnicos se mantenga para la emisión de criterios de campeonatos regionales, de esta forma los criterios de Juegos Parapanamericanos y Europeos mantienen esta distribución.

\section{METODOLOGÍA}

Para el desarrollo de este articulo, se seleccionaron textos deportivos del Comité Olímpico Internacional y del Comité Paralímpico Internacional; se tomaron como base los criterios de selección a los Juegos Paralímpicos con las diferentes versiones de los mismos y a partir de la experiencia profesional del autor, se analizaron los criterios y su evolución, para llegar a la deducción de cambios en la organización deporte nacional.

\section{DISCUSIÓN}

Desde la realización de los primeros juegos paralímpicos, en 1960, los criterios de participación han estado presentes; en sus primeras versiones sólo participaban deportistas en silla de ruedas con lesiones medulares; sin embargo, en los juegos realizados en Toronto 1976, participaron los primeros atletas que no tenían lesión de médula espinal en pruebas con opción a medalla para atletas ciegos y con amputaciones (IPC, 2000). Desde esta época iniciaron los primeros análisis sobre participaciones de deportistas discapacitados en los juegos; así, con el tiempo, los criterios de selección han venido evolucionando y con ellos los temas de clasificación funcional y capacitación a nivel mundial.

La génesis de esta evolución del deporte paralímpico (Sansbury, 2004) ha transformado la participación en cada deporte, de tal forma que todas las discapacidades participan en todos los deportes, con opción de medalla por clasificación funcional, migrando así al sistema tradicional deportivo, el cual, se desarrolla por deporte; esta situación ha consolidado la especialización de técnicos, médicos y clasificadores, potencializando el progreso de los mismos. Por estas razones, los criterios de selección a las paralimpiadas se encuentran en su mejor estado de estructura y de organización.

Los criterios de Londres están proyectados teniendo en cuenta la evolución del deporte paralímpico del mundo; sin embargo, Colombia aun hace grandes esfuerzos por alinearse con éstos, ya que no ha conseguido desarrollar una estructura financieramente sostenible; pues aunque el Estado colombiano se encuentra en responsabilidad de apoyar y de fomentar el desarrollo del deporte, a nivel nacional e internacional, el recurso económico es insuficiente, unido a las situaciones que afrontan la mayoría de organismos deportivos del país de poca gestión con la empresa privada y manejo de intereses personales, que promueven la desunión y poco sentido de comunidad en el sector, dando como resultado la pérdida de oportunidades en la consecución de cupos a eventos de esta envergadura; sin embargo, los efectos provocados por las situaciones económicas del país y de sus organismos deportivos, se deben ir solventado al tiempo con los cambios estructurales que requieren las leyes del deporte y su organización, al contemplar la migración de los deportes paralímpicos a las federaciones de deporte convencional, tal como sucede en la actualidad en el caso del Ciclismo mundial, con el gobierno de la UCI, en el paracycling y de otras disciplinas, donde este progreso ya se consolidó y trajo enor- 
Cuadro 4. Reasignación de plazas por deporte. Adaptado de Página Oficial IPC.

\begin{tabular}{|c|c|}
\hline DEPORTE & MÉTODO DE REASIGNACIÓN DE PLAZAS \\
\hline Atletismo & $\begin{array}{l}\text { Las plazas no utilizadas o no confirmadas por ningún NPC son reasignadas, a través del método } \\
\text { de asignación, por invitación de la Comisión Bipartita. }\end{array}$ \\
\hline Ciclismo & $\begin{array}{l}\text { Las plazas no utilizadas o no confirmadas por ningún NPC son reasignadas, a través del método } \\
\text { de asignación, por invitación de la Comisión Bipartita. }\end{array}$ \\
\hline Natación & $\begin{array}{l}\text { Las plazas no utilizadas o no confirmadas por ningún NPC son reasignadas, a través del método } \\
\text { de asignación, por invitación de la Comisión Bipartita. }\end{array}$ \\
\hline $\begin{array}{l}\text { Esgrima en Silla de } \\
\text { Ruedas }\end{array}$ & $\begin{array}{l}\text { Las plazas no utilizadas o no confirmadas por ningún NPC serán reasignadas utilizando el Ranking } \\
\text { Mundial de Esgrima en Silla de Ruedas de IWAS, que se cierra el } 29 \text { de febrero de } 2012 \text {. }\end{array}$ \\
\hline Tiro con Arco & $\begin{array}{l}\text { Plazas asignadas al país anfitrión; plazas asignadas a partir de los Campeonatos del Mundo de } \\
\text { Tiro con Arco Paralímpico de la FITA 2011; plazas asignadas a partir de los Campeonatos Regio- } \\
\text { nales de Tiro con Arco Paralímpico de la FITA 2010/2011; plazas asignadas a partir del Torneo de } \\
\text { Clasificación de Tiro con Arco Paralímpico de la FITA 2011. }\end{array}$ \\
\hline Tenis de Mesa & $\begin{array}{l}\text { Plazas asignadas en los Campeonatos Regionales de Tenis de Mesa Paralímpico de 2011; plazas } \\
\text { asignadas a partir del Ranking Mundial Masculino y Femenino de Tenis de Mesa Paralímpico de la } \\
\text { ITTF. }\end{array}$ \\
\hline Tiro & $\begin{array}{l}\text { Las plazas no utilizadas o no confirmadas por ningún NPC son reasignadas, a través del método } \\
\text { de asignación, por invitación de la Comisión Bipartita. }\end{array}$ \\
\hline Boccia & $\begin{array}{l}\text { Asignación por las Listas del Ranking de Clasificación Paralímpica de Parejas y Equipos de Boccia } \\
\text { de CPISRA; asignación por las Listas del Ranking Mundial Individual de Boccia de CPISRA. }\end{array}$ \\
\hline Fútbol 5 & $\begin{array}{l}\text { Plazas asignadas en los Campeonatos del Mundo de Fútbol-5 de IBSA 2010; plazas asignadas al } \\
\text { país anfitrión; plazas asignadas en los Campeonatos Regionales de Fútbol-5 de IBSA } 2011 .\end{array}$ \\
\hline Remo & $\begin{array}{l}\text { Las plazas de clasificación no utilizadas por un NPC serán asignadas al NPC mejor situado en el } \\
\text { ranking, En el caso que no se puedan asignar las plazas por el método anterior, serán reasignadas } \\
\text { a discreción del Comité Ejecutivo de la FISA, en consulta con el IPC. }\end{array}$ \\
\hline Ecuestre & $\begin{array}{l}\text { Plazas asignadas en los Campeonatos del Mundo 2010; plazas asignadas a partir del Ranking por } \\
\text { Equipos de la FEI; plazas asignadas a partir del Ranking Individual de la FEI; plazas asignadas al } \\
\text { país anfitrión. }\end{array}$ \\
\hline Vela & $\begin{array}{l}\text { Asignaciones por los Campeonatos del Mundo de Vela para discapacitados de la IFDS de } 2010 \text { y } \\
\text { 2011; asignación al país anfitrión. }\end{array}$ \\
\hline $\begin{array}{l}\text { Tenis en Silla de } \\
\text { Ruedas }\end{array}$ & $\begin{array}{l}\text { Las plazas de clasificación conseguidas que no sean utilizadas serán reasignadas por la ITF al de- } \\
\text { portista mejor situado en la lista del Ranking Mundial en Individuales de Tenis en Silla de Ruedas, } \\
\text { que se cierre el } 21 \text { de mayo de } 2012 \text {. }\end{array}$ \\
\hline Goalball & $\begin{array}{l}\text { Plazas asignadas en el Torneo de Clasificación Paralímpica de Goalball IBSA 2011; plazas asigna- } \\
\text { das al país anfitrión. }\end{array}$ \\
\hline $\begin{array}{l}\text { Baloncesto en Silla } \\
\text { de Ruedas }\end{array}$ & $\begin{array}{l}\text { Las plazas de clasificación que no sean utilizadas serán reasignadas a discreción de la IWBF, con } \\
\text { la aprobación del IPC, tratando de mantener el equilibrio en la representación zonal. }\end{array}$ \\
\hline Judo & $\begin{array}{l}\text { Las plazas de clasificación que no sean utilizadas por los NPC's serán reasignadas al deportista } \\
\text { mejor ubicado en la correspondiente categoría de peso en el Ranking Mundial de Judo de IBSA, } \\
\text { que se cierre el } 31 \text { de diciembre de } 2011 \text {. }\end{array}$ \\
\hline Fútbol 7 & $\begin{array}{l}\text { Las plazas de clasificación que no sean utilizadas serán reasignadas al equipo mejor ubicado en el } \\
\text { ranking de los Campeonatos del Mundo de Fútbol - } 7 \text { CP-ISRA } 2011 \text {. }\end{array}$ \\
\hline
\end{tabular}


mes beneficios al deporte paralímpico mundial. Los beneficios de esta migración, a nivel nacional, estarían dados frente al fortalecimiento en el desarrollo técnico de los deportistas, especialización por deporte de entrenadores, deportistas y personal médico; los impases que podrían existir en este camino serían el poco conocimiento de las particularidades del deporte paralímpico en las federaciones convencionales y el desconocimiento sobre el potencial del deporte paralímpico colombiano, a nivel mundial versus el deporte convencional colombiano, a nivel mundial.

Pero, ¿están los organismos del deporte paralímpico y convencional preparados para unirse y cooperar en el desarrollo y fortalecimiento del deporte paralímpico en los niveles nacionales e internacionales? Sí, estos casos de organización y de apoyo ya se han venido gestando en Colombia, bajo la tutela de dirigentes, pero aun así, todavía se encuentran detalles de organización y de regencia sin definir en las federaciones convencionales y paralímpicas.

Para terminar, se deja a consideración la siguiente frase, proclamada en los Juegos de Barcelona, 1992: "Si el Olimpismo es una filosofía de vida, que exalta y combina en un conjunto armónico las cualidades del cuerpo, la voluntad y el espíritu (Carta Olímpica. Principio Fundamental núm. 2) entonces son muy pocos los argumentos y la necesidad de utilizar una expresión distinta, Paralimpismo, para denominar una ideología que habla del mismo principio en todos los sentidos" (Landry, 1995).

Conflicto de intereses: La autora declara que no existe ningún conflicto de intereses que ponga en riesgo la validez de los resultados presentados.

\section{BIBLIOGRAFÍA}

1. CAYUELA MALDONADO, M.J. 1997. Los efectos sociales del deporte: ocio, integración, socialización, violencia y educación. Barcelona: Centre d'Estudis Olímpics UAB. Disponible desde Internet en: http:// olympicstudies.uab.es/pdf/wp060_spa.pdf (con acceso 15/01/2012).

2. CPE. 2012. Dossier Jefes de Misión Juegos Paralímpicos Londres 2012. Disponible desde Internet en: http:// www.paralimpicos.es/web/2012LONPV/manuales/Londres\%202012\%20-\%20Dossier\%20de\%20 Jefes\%20de\%20Misión\%20-\%20Español.pdf (con acceso 10/01/2012).

3. CPE. 2012. Deportes para minusválidos físicos psíquicos y sensoriales, 1994. http://www.paralimpicos.es/web/ revista/podium7.pdf (con acceso 10/01/2012).
4. CPE. 2012. Guía Explicativa de los deportes en Londres 2012. Guía sobre Atletismo. Disponible desde Internet en: http://www.paralimpicos.es/web/2012LONPV/ deportes/atletismo/Criterios\%20de\%20Clasificacion\%20IPC\%20Atletismo\%20-\%20Español.pdf (con acceso 10/01/2012).

5. CPE. 2012. Guía Explicativa de los deportes en Londres 2012. Guía sobre Baloncesto. Disponible desde Internet en http://www.paralimpicos.es/ web/2012LONPV/deportes/baloncesto/Criterios\%20 de\%20Clasificacion\%20IPC\%20Baloncesto\%20-\%20 Español.pdf (con acceso 10/01/2012).

6. CPE. 2012. Guía Explicativa de los deportes en Londres 2012. Guía sobre Boccia. Disponible desde Internet en: http://www.paralimpicos.es/web/2012LONPV/deportes/boccia/Criterios\%20de\%20Clasificacion\%20 IPC\%20Boccia\%20-\%20Español.pdf (con acceso 10/01/2012).

7. CPE. 2012. Guía Explicativa de los deportes en Londres 2012. Guía sobre Ciclismo. Disponible desde Internet en: http://www.paralimpicos.es/web/2012LONPV/deportes/ciclismo/Criterios\%20de\%20Clasificacion\%20 IPC\%20Ciclismo\%20-\%20Español.pdf (con acceso 10/01/2012).

8. CPE. 2012. Guía Explicativa de los deportes en Londres 2012. Guía sobre Esgrima. Disponible desde Internet en: http://www.paralimpicos.es/web/2012LONPV/deportes/esgrima/Criterios\%20de\%20Clasificacion $\% 20$ IPC\%20Esgrima\%20-\%20Español.pdf (con acceso 10/01/2012).

9. CPE. 2012. Guía Explicativa de los deportes en Londres 2012. Guía sobre Futbol 5. Disponible desde Internet en: http://www.paralimpicos.es/web/2012LONPV/deportes/futbol5/Criterios\%20de\%20Clasificación\%20 IPC\%20Futbol\%205\%20-\%20Español.pdf (con acceso $10 / 01 / 2012$ ).

10. CPE. 2012. Guía Explicativa de los deportes en Londres 2012. Guía sobre Futbol 7. Disponible desde Internet en: http://www.paralimpicos.es/web/2012LONPV/deportes/futbol7/Criterios\%20de\%20Clasificación\%20 IPC\%20Fútbol\%207\%20-\%20Español.pdf (con acceso 10/01/2012).

11. CPE. 2012. Guía Explicativa de los deportes en Londres 2012. Guía sobre Goalball. Disponible desde Internet en: http://www.paralimpicos.es/web/2012LONPV/deportes/goalball/Criterios\%20de\%20Clasificación\%20 IPC\%20Goalball\%20-\%20Español.pdf (con acceso 10/01/2012). 
12. CPE. 2012. Guía Explicativa de los deportes en Londres 2012. Guía sobre Levantamiento de Pesas. Disponible desde Internet en: http:/www.paralimpicos.es/ web/2012LONPV/deportes/halterofilia/Criterios\%20 de\%20Clasificacion\%20IPC\%20Halterofilia\%20-\%20 Español.pdf (con acceso 10/01/2012).

13. CPE. 2012. Guía Explicativa de los deportes en Londres 2012. Guía sobre Hípica. Disponible desde Internet en: http://www.paralimpicos.es/web/2012LONPV/deportes/hipica/Criterios\%20de\%20Clasificación\%20 IPC\%20Hípica\%20-\%20Español.pdf (con acceso 10/01/2012).

14. CPE. 2012. Guía Explicativa de los deportes en Londres 2012. Guía sobre Judo. Disponible desde Internet en: http://www.paralimpicos.es/web/2012LONPV/ deportes/judo/Criterios\%20de\%20Clasificacion\%20 IPC\%20Judo\%20-\%20Español.pdf (con acceso 10/01/2012).

15. CPE. 2012. Guía Explicativa de los deportes en Londres 2012. Guía sobre Natación. Disponible desde Internet en: http://www.paralimpicos.es/web/2012LONPV/ deportes/natacion/Criterios\%20de\%20Clasificacion\%20IPC\%20Natación\%20-\%20Español.pdf (con acceso 10/01/2012).

16. CPE. 2012. Guía Explicativa de los deportes en Londres 2012. Guía sobre Remo. Disponible desde Internet en: http://www.paralimpicos.es/web/2012LONPV/ deportes/remo/Criterios\%20de\%20Clasificacion\%20 IPC\%20Remo\%20-\%20Español.pdf (con acceso 10/01/2012).

17. CPE. 2012. Guía Explicativa de los deportes en Londres 2012. Guía sobre Rugby. Disponible desde Internet en: http://www.paralimpicos.es/web/2012LONPV/ deportes/rugby/Criterios\%20de\%20Clasificacion\%20 IPC\%20Rugby\%20-\%20Inglés.pdf (con acceso 10/01/2012).

18. CPE. 2012. Guía Explicativa de los deportes en Londres 2012. Guía sobre Tenis en SR. Disponible desde Internet en: http:/www.paralimpicos.es/ web/2012LONPV/deportes/tenis/Criterios\%20de\%20 Clasificacion\%20IPC\%20Tenis\%20-\%20Español.pdf (con acceso 10/01/2012).

19. CPE. 2012. Guía Explicativa de los deportes en Londres 2012. Guía sobre Tenis de Mesa. Disponible desde Internet en: http:/www.paralimpicos.es/ web/2012LONPV/deportes/tenismesa/Criterios\%20 de\%20Clasificacion\%20IPC\%20Tenis\%20de\%20 mesa\%20-\%20Español.pdf (con acceso 10/01/2012).
20. CPE. 2012. Guía Explicativa de los deportes en Londres 2012. Guía sobre Tiro con Arco. Disponible desde Internet en: http://www.paralimpicos. es/web/2012LONPV/deportes/tarco/Criterios\%20 de\%20Clasificacion\%20IPC\%20Tiro\%20con\%20 arco\%20-\%20Español.pdf (con acceso 11/01/2012).

21. CPE. 2012. Guía Explicativa de los deportes en Londres 2012. Guía sobre Tiro Olímpico. Disponible desde Internet en: http://www.paralimpicos.es/ web/2012LONPV/deportes/tolimpico/Criterios\%20 de\%20Clasificacion\%20IPC\%20Tiro\%20olímpico\%20-\%20Español.pdf (con acceso 11/01/2012).

22. CPE. 2012. Guía Explicativa de los deportes en Londres 2012. Guía sobre Vela. Disponible desde Internet en: http://www.paralimpicos.es/web/2012LONPV/ deportes/vela/Criterios\%20de\%20Clasificacion\%20 IPC\%20Vela\%20-\%20Español.pdf (con acceso 11/01/2012).

23. CPE. 2012. Guía Explicativa de los deportes en Londres 2012. Guía sobre Voleibol Sentado. Disponible desde Internet en: http://www.paralimpicos.es/ web/2012LONPV/deportes/voleibol/Criterios\%20 de\%20Clasificacion\%20IPC\%20Voleibol\%20-\%20Inglés.pdf (con acceso 11/01/2012).

24. CPE. 2012. Calendario de los Juegos Paralímpicos Londres 2012. Disponible desde Internet en: http://www. paralimpicos.es/web/2012LONPV/calendario/calendario_pdf (con acceso 02/02/12).

25. DECRETO 641 DE 2001 de abril 16. Diario Oficial No. 44394, del 20 de abril de 2001. Ministerio de Educación Nacional. Por el cual se reglamenta la Ley 582 de 2000 sobre deporte asociado de personas con limitaciones físicas, mentales o sensoriales. $6 \mathrm{p}$.

26. IPC. International Paralympic Committee. 2011. Estructura. Disponible desde Internet en: http://www. paralympic.org/IPC/Organization/ (con acceso 15/01/12).

27. IPC. 2011. Deportes. Disponible desde Internet en: http://www.paralympic.org/Sport/IPC_Sports/index. html (con acceso 15/01/2012).

28. IPC. 2011. Deportes de Organizaciones Internacionales de Deportes para personas discapacitadas. Disponible desde Internet en: http://www.paralympic. org/Sport/IOSD_Sports/index.html (con acceso 15/01/2012).

29. IPC. 2011. Deportes de Federaciones Internacionales por Deporte Disponible desde Internet en: desde 
http://www.paralympic.org/Sport/IF_Sports/index. html (con acceso 15/01/2012).

30. IPC. 2011. Criterios de clasificación Londres 2012, Versión febrero de 2011. Disponible desde Internet en: http://www.paralympic.org/sites/default/files/document/1202081305295092011 1216 Updates and Additions Summary London PG Qualification_Güuide.pdf (con acceso 10/12/2011).

31. IPC. 2011. Criterios de clasificación Londres 2012. Versión diciembre de 2011. Disponible desde Internet en: http://www.paralympic.org/Events/London2012/ Qualification (con acceso 10/12/2011).

32. IPC. 2011. Criterios de clasificación Londres 2012 - Atletismo. Disponible desde Internet en: http://www. paralympic.org/export/sites/default/Paralympic_Games/London_2012/Qualification_Criteria/2011_08_ Athletics_London_2012_PG_Qualification_Criteria_Updated_Master.p̄ōf (con acceso 15/01/201̄2).

33. IPC. 2011. Criterios de clasificación Londres 2012 - Arquería. Disponible desde Internet en: http://www. paralympic.org/export/sites/default/Paralympic_Games/London_2012/Qualification_Criteria/2011_04_ Archery_London_2012 PG QC Final_Version_U-'date.pdf (con acceso 15/01/2012).

34. IPC. 2011. Criterios de clasificación Londres 2012 Boccia. Disponible desde Internet en: http://www. paralympic.org/export/sites/default/Paralympic_Games/London_2012/Qualification_Criteria/2011_04 Boccia_London_2012_PG_Qualification_Criteria_ Final_update.pdf (con acceso 15/01/2012).

35. IPC. 2011. Criterios de clasificación Londres 2012 - Ciclismo. Disponible desde Internet en: http://www. paralympic.org/export/sites/default/Paralympic_Games/London_2012/Qualification_Criteria/2011_02 Cycling_London_2012_PG_Qualification_Criteria_ Final_Update.pdf (con acceso 15/01/2012).

36. IPC. 2011. Criterios de clasificación Londres 2012 Ecuestre. Disponible desde Internet en: http://www. paralympic.org/export/sites/default/Paralympic_Games/London_2012/Qualification_Criteria/2011_04_ Equestrian_London_2012_PG_Qualification_Čriteria_Update.pdf (con acceso 15/01/2012).

37. IPC. 2011. Criterios de clasificación Londres 2012 Fútbol 5. Disponible desde Internet en: http://www. paralympic.org/export/sites/default/Paralympic_Games/London_2012/Qualification_Criteria/2011_05_
Football 5 a Side London 2012 PG Qualification_Criteria_Final_U_update.pdf (con ${ }^{-}$acceso 15/01/2012).

38. IPC. 2011. Criterios de clasificación Londres 2012 Fútbol 7. Disponible desde Internet en: http://www. paralympic.org/export/sites/default/Paralympic_Games/London 2012/Qualification Criteria/2011 02 Ft-7-Aside london_2012_pgside_London_2012_ PG_Qualification_Criteria_Final_Update.pdf $\quad$ (con acceso 15/01/2012).

39. IPC. 2011. Criterios de clasificación Londres 2012 Goalball. Disponible desde Internet en: http://www. paralympic.org/export/sites/default/Paralympic_Games/London 2012/Qualification_Criteria/2011_07 Goalball_London_2012_PG_Qualification_Criteria_ Final_Update.pdf (con acceso 15/01/2012).

40. IPC. 2011. Guía de Clasificación Juegos Paralímpicos Londres 2012. Disponible desde Internet en: http:// www.paralympic.org/sites/default/files/document/12 0223112335266 2012+Classification+Guide+2nd +edition.pdf (con acceso 10/12/2011).

41. IPC. 2011. Guía de control dopaje de los Juegos Paralímpicos Londres 2012. Disponible desde Internet en: http://www.paralympic.org/sites/default/files/document/120208111439322_Doping_Control_Guide_for_the_London_2012_Paralympic_Games.pdf (con acceso 10/12/20̄11)

42. IPC. 2011. Comité Organizador para los Juegos Olímpicos de Atenas. 2004. Guía de Clasificación MédicoFuncional, Atenas. 45p.

43. IPC. 2012. Descripción de los deportes Paralímpicos. Disponible desde Internet en: http://www.london2012. com/paralympic-sport (con acceso 15/01/12).

44. IPC. 2000. History of Paralympic Movement. Disponible desde Internet en: www.paralympic.org/ParalympicGames (con acceso 15/03/12).

45. INAS-FID Discapacitados Intelectuales. 2010. Criterios selección a Londres 2012. Disponible desde Internet en: http://www.paralimpicos.es/publicacion/3SC_ Deportes/335SS_Clasitenismesa.html (con acceso $12 / 01 / 12)$.

46. IWASF. 2010. Disponible desde Internet en: http://www. iwasf.com (con acceso 15/01/12).

47. INTERNATIONAL CYCLING UNION. 2009. Criterios a Londres 2012. Para-Cycling. Disponible desde Inter- 
net en: http://www.uci.ch/Modules/BUILTIN/getObject.asp?Menuld = MTI2MzIEObjTypeCode $=$ FILEE type $=$ FILEEid $=$ NTcwMjEELangId=1 (con acceso 12/01/12).

48. INTERNATIONAL BLIND SPORT ASSOCIATIONS IBSA. 2010. Criterios a Londres 2012 - Judo. Disponible desde Internet en: http:/www.ibsa.es/esp/ deportes/judo/londres\%202012\%20guía\%20de\%20 clasificación\%20judo\%20nov\%2009.pdf (con acceso 08/01/12).

49. INTERNATIONAL BLIND SPORT ASSOCIATIONS IBSA. 1994. Capaces de todo, los 15 deportes homologados. Disponible desde Internet en: http://www.ibsa. es/esp/ (con acceso 08/01/12).
50. LANDRY, F. 1995. Paralympic Games and social integration. En: De Moragas Spà, M.; Botella, M. (eds.). The Keys of success: the social, sporting, economic and communications impact of Barcelona'92. Bellaterra: Servei de Publicacions de la Universitat. p.124-138.

51. SAINSBURY, T. 2004. Paralímpicos: pasado, presente y futuro: lecciones universitarias olímpicas. Barcelona: Centre d'Estudis Olímpics (UAB). Cátedra Internacional de Olimpismo (CIO-(UAB). Disponible desde Internet en: http://ceo.uab.cat/lec/pdf/spa_sainsbury. pdf (con acceso 15/01/12).

Recibido: Enero 13 de 2012.

Aceptado: Mayo 5 de 2012 